\title{
Radiculopathy as a complication of ankylosing spondylitis
}

\author{
W. J. K. C UMMING, A N D M. S A U N DER S \\ From the Department of Neurology, Middlesbrough General Hospital, Middlesbrough
}

SUMMARY A cauda equina syndrome in association with ankylosing spondylitis is well recorded. We report the occurrence of an upper limb radiculopathy which progressed to a cauda equina syndrome in association with ankylosing spondylitis.

Neurological complications of ankylosing spondylitis are uncommon and have recently been reviewed (Thomas et al., 1974). We report the occurrence of an upper limb radiculopathy occurring in association with ankylosing spondylitis.

\section{Case report}

The patient (A47966) was well until 1964 when, at the age of 35 years, he developed progressive pain and stiffness in his lower back, noticeable particularly in the early morning. A diagnosis of ankylosing spondylitis was made. Over the next four years, the pain and limitation of back movement spread to the dorsal and cervical regions. In 1970 , because of severe pain, he was treated with deep $x$-ray therapy. Twelve hundred rads were given to each of the cervical, dorsal, lumbar, and sacroiliac regions over a 10 day period. This was followed by marked symptomatic relief. In 1971 he had bilateral costoclavicular pain which was again treated with deep radiation (700 rads as a single dose).

In 1972, at age 43 years, 11 months after the last course of deep $x$-ray therapy, he noticed numbness involving the lateral three fingers of the left hand. Over a four month period the numbness spread to involve the ulnar border of the forearm and all of the hand. Examination confirmed sensory loss to all modalities from C6 to T1 dermatomes on the left. There was mild (MRC grade 4) weakness of grip of the left hand. All deep tendon reflexes were elicitable with reinforcement. The

Address for reprint requests: Dr W. J. K. Cumming, Department of Neurology, Regional Neurological Centre, Newcastle General Hospital, Westgate Road, Newcastle upon Tyne, NE4 6BE, England. Accepted 25 January 1978 rest of the neurological examination was normal. There was limitation of back movement with local tenderness over the sacroiliac joints. Radiology of the cervical, dorsal, and lumbar spine confirmed the ankylosing spondylitis. A myelogram was normal.

The patient was lost to follow-up until January 1977. At that time he gave a history of progression of the sensory abnormalities to affect the ulnar border of the right arm and hand. Examination confirmed the previous sensory abnormalities in the left hand and showed progression of his motor weakness to MRC grade 3. There was sensory loss in the $\mathrm{C} 7 / 8$ dermatomes on the right. All the deep tendon reflexes were now absent and the rest of the examination was normal. Neurophysiological studies were performed (Table) and showed evidence of involvement of all the sensory nerves in the upper limbs, the lesion being distal to or at the dorsal root ganglia. A repeat myelogram was normal, as was the CSF obtained at the time of

Table Nerve conduction velocities

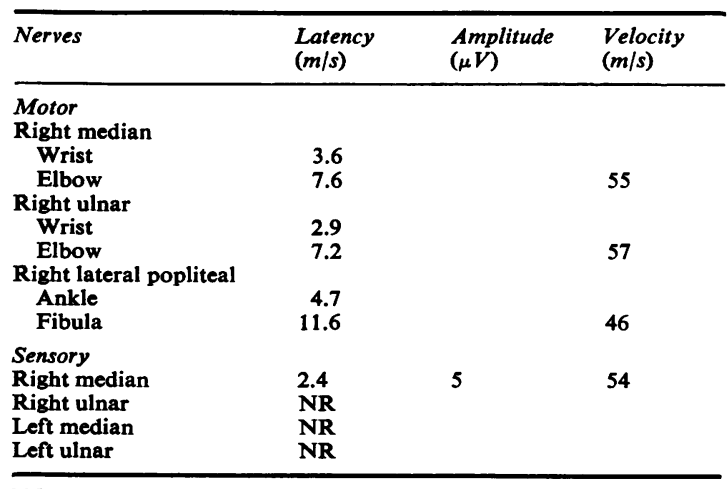

$\mathrm{NR}=$ no response. 
the myelogram. In August 1977, the patient complained of progression of the sensory abnormality to the right leg, and examination confirmed L5 dermatome sensory loss.

\section{Discussion}

This patient had a slowly progressive, predominantly sensory radiculopathy which came on six years after the onset of his ankylosing spondylitis. Nerve root lesions in the presence of extensive bony abnormalities of the spine would not be unexpected, but no evidence of foraminal encroachment was demonstrated in this patient. Two patients with nonprogressive root lesions have been described by Thomas et at. (1974). We do not think that the radiotherapy given to our patient was the cause of his symptoms, since the cervical radiation dose was well within the accepted limits (Pallis et al., 1961). Matthews (1968) and Hassan (1976) have described a cauda equina syndrome in association with ankylosing spondylitis, which has been shown to be caused by posteriorly situated diverticula of the lumbar theca. We believe that two normal myelograms in our patient effectively negate this possibility in the cervical region in his case.

We believe that this patient is now developing the previously described cauda equina syndrome in association with ankylosing spondylitis. We would draw attention to the possibility that similar symptoms can arise from the cervical region and may be the presenting symptoms.

\section{References}

Hassan, I. (1976). Cauda equina syndrome in ankylosing spondylitis: a report of six cases. Journal of Neurology, Neurosurgery, and Psychiatry, 39, 11721178.

Matthews, W. B. (1968). The neurological complications of ankylosing spondylitis. Journal of the Neurological Sciences, 6, 561-573.

Pallis, G. A., Louis, S., and Morgan, R. L. (1961). Radiation myelopathy. Brain, 84, 460-479.

Thomas, D. J., Kendall, M. J., and Whitfield, A. G. W. (1974). Nervous system involvement in ankylosing spondylitis. British Medical Journal, 1, 148-150. 